\title{
CORRESPONDENCE
}

\section{COMMENTS ON "A FIRST LIST OF VESPID WASPS FROM VIETNAM (Hymenoptera: Vespidae)" BY PHAM AND LI (2015)}

\author{
Nguyen Thi Phuong Lien \\ Institute of Ecology and Biological Resources, VAST
}

Citation: Nguyen Thi Phuong Lien, 2016. Correspondence: Comments on "A first list of vespid wasps from Vietnam (Hymenoptera: Vespidae)" by Pham and Li (2015). Tap chi Sinh hoc, 38(3): 408-410. DOI: 10.15625/0866-7160/v38n3.8335.

*Corresponding author: phuonglientit@gmail.com.

Pham and $\mathrm{Li}$ (2015) published a list of vespid wasps from Vietnam on 26 August 2015, which included 109 species in 32 genera of four subfamilies, namely Eumeninae (33 species), Stenogastrinae (10 species), Polistinae (50 species), and Vespinae (16 species) [17].

Presently, based on the data gathered from all references published before Pham and $\mathrm{Li}$ (2015), a total of 131 species of vespid wasp in 39 genera has been recorded from Vietnam, including Eumeninae (56 species), Stenogastrinae (10 species), Polistinae (51 species) and Vespinae (14 species).

Nguyen et al. (2014) [10] was published more than a year before Pham and $\mathrm{Li}$, and provided an annotated distributional checklist of solitary wasps of the subfamily Eumeninae of Vietnam, which listed 45 species in 26 genera, including 13 species and six genera that were newly recorded for Vietnam. In the same year, one more species in the group was described as new in Nguyen \& $\mathrm{Xu}$ (2014) [16] [Okinawepipona nigra Nguyen \& Xu, 2014]. So by the end of 2014, 46 species of Eumeninae were recorded from Vietnam.

By the end of 2014, a total of 74 identified species in 11 genera of social wasps in the three subfamilies Stenogastrinae, Polistinae and Vespinae was recorded from Vietnam, including 10 species in Stenogastrinae, 50 species in Polistinae and 14 species in Vespinae (Nguyen et al., 2006a,b; Nguyen, 2007; Nguyen \& Kojima, 2013; Nguyen, 2014) [14, 15, 12, 4, 2]. Of the 76 species of social wasps listed in
Pham and Li (2015) [17], Vespa auraria Smith, 1852 was synonymized under Vespa velutina Lepeletier, 1836, by Nguyen et al. (2006) [14]. The status of Vespa binghami du Buyson, 1905 was mentioned in Nguyen \& Carpenter (2002) [9] as "the presence of this species in Vietnam, while possible, is not documented", but this species was still listed in Pham \& Li (2015) [17] without any additional information. Thus, only 74 presently recognized species of social wasps were listed in Pham \& Li (2015) [17]. Furthermore, Polistes meadeanus (von Schulthess, 1913) was recorded in Vietnam by Nguyen (2014) [4] but was not listed in Pham \& Li (2015) [17]. Moreover, Polybioides gracilis van der Vecht, 1966, was confirmed to occur in Vietnam (Gia Lai province) according to Nguyen (2013) [3] and Nguyen et al. (2014b) [11], but was also not mentioned in Pham \& $\mathrm{Li}$ (2015) [17].

So if all published literature to end of 2014 is considered, the numbers of all vespid wasps in all four subfamilies given in Pham and $\mathrm{Li}$ (2015) were known to be wrong.

After Nguyen et al. (2014) [10], and by the end of June 2015, several publications on solitary wasps were published, including Nguyen \& Xu (2014) [16], Nguyen (2015a, b, c, d) $[5,6,7,8]$ (all mentioned publications were published by the end of June 2015). Based on those references, a total of 56 solitary wasp species in 28 genera of the subfamily Eumeninae has been recorded from Vietnam, including 44 species listed in Nguyen et al. (2014a) [10] [one taxon, Anterhynchium 
abdominale abdominale (Illiger) was described as new to science in Nguyen (2015c) [7], the species listed in Nguyen \& Xu (2014) [16] [Okinawepipona nigra Nguyen \&Xu, 2014], one species listed in Nguyen (2015a) [5] [Delta conoideum (Gmelin, 1790)], 2 species listed in Nguyen (2015b) [6] [Pararrhynchium striatum Nguyen, 2015 and P. concavum Nguyen, 2015], 3 species listed in Nguyen (2015c) [7] [Anterhynchium punctatum Nguyen, 2015, A. (Dirhynchium) flavolineatum flavolineatum (Smith, 1857) and A. (Dirhynchium) flavomarginatum flavomarginatum (Smith, 1852)], and 5 species listed in Nguyen (2015d) [8] [Eumenes atrophicus (Fabricius, 1798), E. gibbosus Nguyen, 2015, E. inconspicuus Smith, 1858, E. labiatussinicus Giordani Soika, 1941, and E. rubronotatus Pérez, 1905], compared to 32 species of the subfamily listed in Pham \& Li (2015) [17] [of the 33 species of solitary wasps listed in Pham \& Li (2015), Eumenes flavopictus continentalis (Zimmermann, 1931) was synonymized under Phimenes flavopictum flavopictum by Kumar (2013) [1].

By the end of June 2015, a total of 79 identified species in 11 genera of the three social wasp subfamilies Stenogastrinae, Polistinae and Vespinae was recorded from Vietnam, compared to 74 species listed in Pham \& Li (2015) [17]. Of the 79 species, 74 species were recorded from the past up to end of 2014. In addition, 5 species of the genus Parapolybia were listed in Saito-Morooka et al. (2015) [18] [Parapolybia albida Saito-Morooka, Nguyen \& Kojima, $P$. bioculata van der Vecht, 1966, $P$. flava Saito-Morooka, Nguyen \& Kojima, 2015, $P$. nana Saito-Morooka, Nguyen \& Kojima, 2015, and P. tinctipennis (Cameron, 1900)], but not listed in Pham \& Li (2015) [17].

So if all pertinent literature before Pham and Li (2015) was even published was cited, the numbers of all vespid wasps in four subgenera given in Pham and Li (2015) were known to be wrong and out of date.

The distribution records of all species listed in Pham \& Li (2015) were presented in previous publications excluding some additional records of some widely distributed species.
For all of the above reasons, the list given in Pham \& Li (2015) was an incomplete checklist of vespid wasps from Vietnam and contributed little to the knowledge of vespid wasps in Vietnam.

Acknowledgments: The author thanks James M. Carpenter (American Museum of Natural History) for his suggestions on an early draft of the correspondence.

\section{REFERENCES}

1. Kumar P. G., 2013. A taxonomic revision of Phimenes Giordani Soika (Hymenoptera: Vespidae: Eumeninae) of Indian subcontinent. Records of the Zoological Survey of India, 113 (Part-3): 119-135.

2. Nguyen Thi Phuong Lien, 2007. Taxonomic revision and distribution pattern of social wasps (Hymenoptera: Vespidae) in Vietnam. Ph. D thesis, Ibaraki University, Mito, Ibaraki, Japan, 220pp.

3. Nguyen Thi Phuong Lien, 2013. Notes on social wasps (Hymenoptera: Vespidae) in Kon Ka Kinh National Park, Gia Lai province. Proceedings of the $5^{\text {nd }}$ National Scientific Conference on Ecology and Biological Resources Hanoi, 18 October 2013: 543-546. (Vietnamese, summary in English).

4. Nguyen Thi Phuong Lien, 2014. A new record of Polistella (Polistes) species (Hymenoptera: Vespidae: Polistinae) with its nest description from Tay Nguyen plateau, Vietnam. Tap chi Sinh hoc, 36(4): 423-427. http://dx.doi.org/10.15625/08667160/v36n4.6172.

5. Nguyen L. T. P., 2015. Taxonomic notes on the genus Delta de Saussure (Hymenoptera: Vespidae: Eumeninae) from Vietnam. Animal Systematic, Evolution and Diversity, 31 (2): 95-100.

6. Nguyen L. T. P., 2015. Two new species of the genus Pararrhynchium de Saussure (Hymenoptera: Vespidae: Eumeninae) from northern Vietnam. Zootaxa, 3974 (2): 170176. http://dx.doi.org/10.11646/zootaxa. 3974.2 .2 
7. Nguyen L. T. P., 2015. Taxonomic notes on the species of the genus Anterhynchium de Saussure, 1863 (Hymenoptera: Vespidae: Eumeninae) from Vietnam with description of a new species. Zootaxa, 3915(1): 132138. http://dx.doi.org/10.11646/zootaxa. 3915.1.7.

8. Nguyen L. T. P, 2015. Potterwaps of the genus Eumenes Latreille, 1802 (Hymenoptera: Vespidae: Eumeninae) from Vietnam, with description of a new species and key to species. Zootaxa, 3974(4): 564572. http://dx.doi.org/10.11646/zootaxa. 3974.4.7.

9. Nguyen L. T. P., Carpenter J. M., 2002. Vespidae of Vietnam (Insecta: Hymenoptera) I. Vespinae. Journal of the New York Entomological Society, 110: 199-211.

10. Nguyen L. T. P., Dang H. T., Kojima J., Carpenter J. M., 2014. An annotated distributional checklist of solitary wasps of the subfamily Eumeninae (Hymenoptera: Vespidae) of Vietnam. Entomologica Americana, 120(1): 7-17.

11. Nguyen Thi Phuong Lien, Hoang Vu Tru, Pham Thi Hoa, 2014. Diversity of social wasps (Hymenoptera: Vespidae) from four provinces in Tay Nguyen plateau. Proceeding of the 8th Vietnam National Conference on Entomology, Hanoi, April 2014: 910-915. (Vietnamese, summary in English).

12. Nguyen Thi Phuong Lien, Kojima Junichi, 2013. Distribution of social wasps in
Vietnam (Hymenoptera: Vespidae). TAP CHI SINH HOC, 35(3se): 16-25.

13. Nguyen L. T. P., Saito F., Kojima J., Carpenter J. M., 2005. An annotated distributional checklist of social wasps (Hymenoptera: Vespidae) of Viet Nam. Proceedings of the $1^{\text {st }}$ national workshop on ecology and biological resources Hanoi, 17 May 2005: 129-137. (Vietnamese, summary in English).

14. Nguyen L. T. P., Saito F., Kojima J., Carpenter J. M., 2006. Vespidae of Vietnam (Insecta: Hymenoptera) 2. Taxonomic notes on Vespinae. Zoological Science, 23: 95104.

15. Nguyen L. T. P, Saito F., Kojima J., Carpenter J. M., 2006. Vespidae (Hymenoptera) of Viet Nam 3. Synoptic key to Vietnamese species of the polistine genus Ropalidia, with notes on taxonomy and distribution. Entomological Science, 9: 93107.

16. Nguyen L. T. P., Xu Z. F., 2014. Two new species of the genus Okinawepipona Yamane (Hymenoptera: Vespidae: Eumeninae) from Vietnam and China. Zootaxa, 3795 (1): 38-044.

17. Pham P. H., Li T. J., 2015. A first list of vespid wasps from Vietnam (Hymenoptera: Vespidae). Russian Entomological Journal, 24(2): 133-144.

18. Saito-Morooka F., Nguyen L. T. P., Kojima J., 2015. Review of the paper wasps of the Parapolybiaindica species-group (Hymenoptera: Vespidae, Polistinae) in eastern parts of Asia. Zootaxa, 3947(2): 215-235.

Received 15 May 2016, accepted 20 September 2016 